\title{
Effect of infiltrants on the electrical resistivity of reaction-sintered silicon carbide
}

\author{
V N MULAY, N KISHAN REDDY and M A JALEEL \\ Regional Research Laboratory, Hyderabad 500 007, India \\ MS received 11 July 1988; revised 8 May 1989
}

\begin{abstract}
The effect of infiltrants on the electrical resistivity of reaction-sintered silicon carbide, at temperatures ranging from $\mathrm{RT}$ to $1000^{\circ} \mathrm{C}$, has been studied. Electrical resistivity decreases with increase in temperature up to $1000^{\circ} \mathrm{C}$ in $\mathrm{VC}$ and $\mathrm{MoSi}_{2}$, whercas minimum electrical resistivity is observed at $\approx 600^{\circ} \mathrm{C}$ in $\mathrm{B}_{4} \mathrm{C}$ infiltrant.
\end{abstract}

Keywords. Reaction-sintered silicon carbide; electrical resistivity; infiltrants.

\section{Introduction}

Reaction-sintered silicon carbide (RSSC) is an exceptional material which has extensive applications in rocket nozzles, radiant heater tubes, chemical plant components, nuclear cladding and wear resistant parts. It is also used for ceramic gas-turbine components because of its outstanding chemical and mechanical properties at high temperatures. RSSC materials, generally produced from a compacted mixture of $\mathrm{SiC}$ particles and carbon by introducing molten silicon to convert the carbon into $\mathrm{SiC}$, form bonds with the original $\mathrm{SiC}$ crystals as well as amongst themselves (Pick 1979; Popper 1960; Forrest et al 1972). The present study describes the effect of infiltrants like VC, $\mathrm{B}_{4} \mathrm{C}$ and $\mathrm{MoSi}_{2}$ on the electrical resistivity of reaction-sintered silicon carbide.

\section{Experimental}

Green silicon carbide ( $\alpha$-variety, $\approx 70 \%)$, graphite $(\approx 30 \%)$ and infiltrant $(\approx 5 \%)$ were used for the preparation of batches. Various compositions were weighed and mixed and the dried mixtures were again mixed with the requisite amount of binder. Small rods of $1 \mathrm{~cm}$ dia were prepared from the above batches under a pressure of $500 \mathrm{~kg} / \mathrm{cm}^{2}$ and were further dried and used for green density measurements. The rods were subjected to the vapours of pure silicon at elevated temperatures $(1600$ $1700^{\circ} \mathrm{C}$ ) under partial-vacuum conditions. The infiltrated reaction-sintered SiC rods which had some free silicon adhering to the surface were removed and brought to the exact dimensions by centreless grinding and were used for electrical resistivity measurements. The pellets of RSSC infiltrated with $5 \%$ each of $\mathrm{VC}, \mathrm{B}_{4} \mathrm{C}$ and $\mathrm{MoSi}_{2}$ were studied for crystal structure by using Phillips X-ray Diffractometer (PW 1051). The results are reported in table 2 below.

The apparatus constructed for the measurement of electrical resistivity is based on the two-probe method. It essentially consists of a sample holder, graphite electrodes, an electrically heated furnace, a temperature measuring device and a digital multimeter. Rods of $1 \mathrm{~cm}$ dia and 2 to $3 \mathrm{~cm}$ length were used for the experiment. The resistivity was measured in the range varying from room temperature to $1000^{\circ} \mathrm{C}$ by using the formula 


$$
\rho=R A / L,
$$

where $R$ is the resistance, $A$ the cross-sectional area and $L$ the length of the specimen.

\section{Results and discussions}

The bulk density, porosity and water absorption data given in table 1 show that the bulk density varies from 2.97 to $3.13 \mathrm{~g} / \mathrm{cm}^{3}$ and the porosity from 0.02 to $1.12 \%$ for a doped and undoped reaction-sintered silicon carbide. XRD data as given in table 2 indicate the corresponding strong lines of the respective infiltrants. Thus the strong lines, viz. 2.41 and 2.09 of $\mathrm{VC}, 2.57$ and 2.38 of $\mathrm{B}_{4} \mathrm{C}$ and 3.37 and 2.17 of $\mathrm{MoSi}_{2}$, are observed in the respective XRD data. However, the intensities are weak due to the presence of these infiltrants in the RSSC in minor quantities $(5 \%)$. These XRD data clearly show the presence of infiltrants in the prepared materials. Microstructure studies on polished specimens of RSSC and those infiltrated with $5 \%$ of $\mathrm{VC}, \mathrm{B}_{4} \mathrm{C}$ and $\mathrm{MoSi}_{2}$ were carried out by using a scanning electron microscope. Micrographs of RSSC and RSSC with $5 \% \mathrm{MoSi}_{2}$ are given in figures 1 and 2 respectively. It is clearly seen from figure 2 that the infiltrant is mostly

Table 1. Physical properties of doped and undoped reactionsintered silicon carbide.

\begin{tabular}{lccc}
\hline Composition & $\begin{array}{c}\text { Porosity } \\
(\%)\end{array}$ & $\begin{array}{c}\text { Wensity } \\
\left(\mathrm{g} / \mathrm{cm}^{3}\right)\end{array}$ & $\begin{array}{c}\text { Water } \\
\text { absorption } \\
(\%)\end{array}$ \\
\hline RSSC & 0.98 & 3.09 & $0 \cdot 32$ \\
RSSC $+5 \%$ VC & 0.02 & $3 \cdot 13$ & 0.005 \\
RSSC $+5 \% \mathrm{~B}_{4} \mathrm{C}$ & $1 \cdot 12$ & $2 \cdot 97$ & $0 \cdot 29$ \\
RSSC $+5 \% \mathrm{MoSi}_{2}$ & $0 \cdot 29$ & $3 \cdot 10$ & 0.07 \\
\hline
\end{tabular}

Table 2. XRD data of infiltrated reaction-sintered silicon carbide.

\begin{tabular}{|c|c|c|c|c|c|}
\hline \multicolumn{2}{|c|}{$\mathrm{RSSC}+5 \% \mathrm{VC}$} & \multicolumn{2}{|c|}{$\mathrm{RSSC}+5 \% \mathrm{~B}_{4} \mathrm{C}$} & \multicolumn{2}{|c|}{$\mathrm{RSSC}+5 \% \mathrm{MoSi}_{2}$} \\
\hline$d$ & $I / I_{1}$ & $d$ & $I / I_{1}$ & $\dot{d}$ & $I / I_{1}$ \\
\hline $3 \cdot 11^{@}$ & 19 & $3 \cdot 34$ & 6 & $3.37^{*}$ & 8 \\
\hline 2.77 & 15 & $3 \cdot 11^{@}$ & 12 & $3 \cdot 11 @$ & 18 \\
\hline $2 \cdot 56$ & 10 & $2 \cdot 60$ & 27 & $2 \cdot 61$ & 34 \\
\hline $2 \cdot 50$ & 100 & $2 \cdot 57^{*}$ & 12 & 2.55 & 16 \\
\hline $2 \cdot 41^{*}$ & 13 & $2 \cdot 50$ & 100 & $2 \cdot 50$ & 100 \\
\hline $2 \cdot 34$ & 22 & $2 \cdot 38^{*}$ & 15 & $2 \cdot 34$ & 30 \\
\hline $2 \cdot 16$ & 14 & $2 \cdot 34$ & 33 & $2 \cdot 31$ & 10 \\
\hline $2.09 *$ & 11 & $2 \cdot 16$ & 12 & $2 \cdot 17^{*}$ & 14 \\
\hline $1.91^{@}$ & 9 & 1.99 & 7 & 1.99 & 7 \\
\hline 1.67 & 5 & $1.91^{\oplus}$ & 9 & $1.91^{@}$ & 14 \\
\hline 1.63 & 7 & $1 \cdot 66$ & 7 & 1.67 & 8 \\
\hline 1.53 & 41 & $1 \cdot 63$ & 6 & 1.63 & 7 \\
\hline 1.42 & 9 & 1.53 & 41 & 1.53 & 33 \\
\hline 1.41 & 9 & $1 \cdot 41$ & 10 & $1 \cdot 41$ & 16 \\
\hline
\end{tabular}

*Lines due to respective infiltrants; ${ }^{1}$ lines due to silicon. 


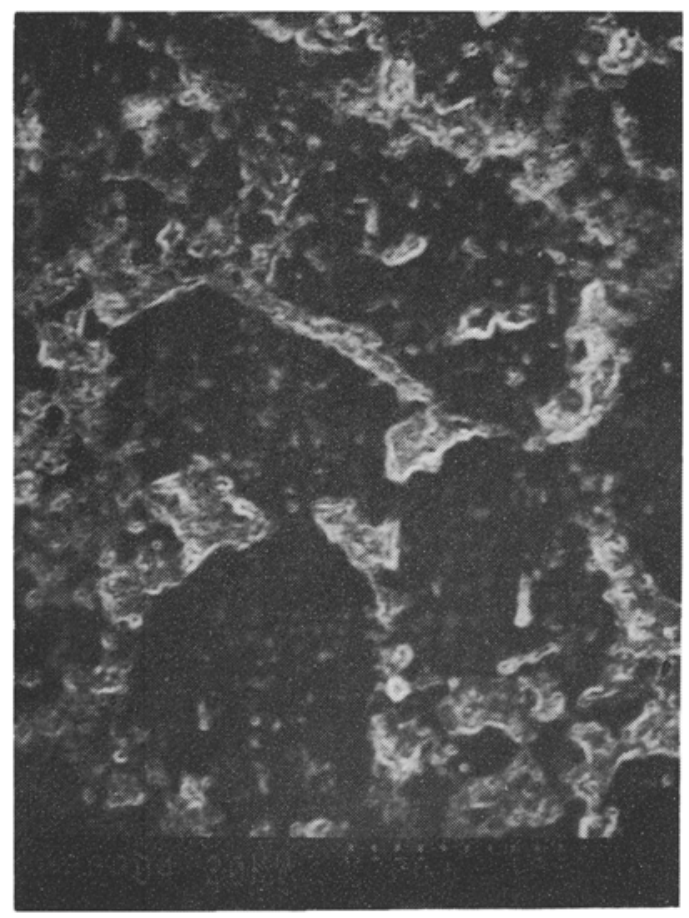

Figure 1. Scanning electron micrograph of reaction-sintered silicon carbide.

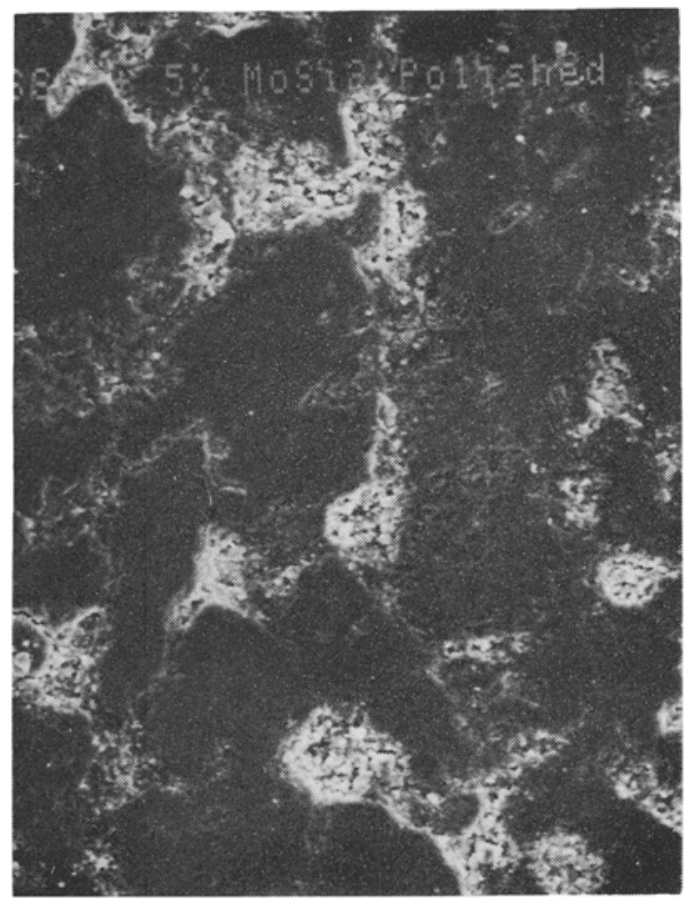

Figure 2. Scanning electron micrograph of reaction sintered silicon carbide with $5 \%$ $\mathrm{MoSi}_{2}$. 
segregated in the white silicon phase in the form of black particles. The grey region of silicon carbide does not show the presence of infiltrants. Similar microstructural patterns are also observed in other infiltrated samples. Electrical resistivity data of reaction-sintered silicon carbide and those infiltrated with $5 \%$ each of $\mathrm{B}_{4} \mathrm{C}, \mathrm{VC}$ and $\mathrm{MoSi}_{2}$, given in table 3, as a function of temperature up to $1000^{\circ} \mathrm{C}$ show that the room temperature electrical resistivity has been considerably reduced by the addition of infiltrants. With the addition of $5 \% \mathrm{~B}_{4} \mathrm{C}$, resistivity has been reduced six-fold. Some of the earlier workers (Kuznetsova and Bresker 1972) observed an increase in the resistivity of the $\mathrm{SiC}$ heating element on adding $5 \% \mathrm{~B}_{4} \mathrm{C}$. Similarly Oleinik and Shipilova (1975) also observed an order of magnitude increase with $B$ as a dopant. Hot-pressed silicon carbide samples using $B$ as a sintering aid also exhibited an increase in the electrical resistivity. An increase in resistivity on adding 0.1 and $1 \%$ of $\mathrm{B}_{4} \mathrm{C}$ either to the slip or the silicon has been reported (North and Gilchrist 1981). No literature data is available on the addition of VC and $\mathrm{MoSi}_{2}$ to reaction-sintered silicon carbide. We have observed approximately $60 \%$ and $50 \%$ decreases, with $5 \%$ additions of $\mathrm{VC}$ and $\mathrm{MoSi}_{2}$, respectively.

Table 3 shows the change of $\rho$ with increase in temperature up to $1000^{\circ} \mathrm{C}$. Interestingly it is observed that $\rho$ reduces from 0.6 to $0.4 \mathrm{ohm} \mathrm{cm}$ at $1000^{\circ} \mathrm{C}$ (approximately 33\% decrease). Figure 3 summarizes the results and shows the energy distribution of the charge carriers with increase in thermal excitations.

The curve for the undoped RSSC exhibits almost a linear decrease in electrical resistivity with a slight change of slope around $300^{\circ} \mathrm{C}$. The convergence of electrical resistivity at around $900^{\circ} \mathrm{C}$ for undoped and doped $\mathrm{RSSC}$ has been reported (North and Gilchrist 1981). Such behaviour is observed only in the case of $5 \% \mathrm{MoSi}_{2}$ and $5 \% \mathrm{VC}$ infiltrants. This is due to the overtaking by intrinsic effects i.e. electron and hole charge carriers to an impurity-induced charge carriers and scattering centres. However, in an undoped sample, the unintentional impurities present in the starting material probably contribute to the electrical conductivity. Peculiar behaviour is observed with the addition of $5 \% \mathrm{~B}_{4} \mathrm{C}$. At approximately $400^{\circ} \mathrm{C}$ there is a sharp decrease in $\rho$ reaching below the range of the measuring unit. However, further increase in the temperature increases the resistivity. This increased value of $\rho$

Table 3. Electrical resistivity data of reaction-sintered silicon carbide with and without dopants.

\begin{tabular}{lcccc}
\hline \multirow{2}{*}{$\begin{array}{l}\text { Temperature } \\
\left({ }^{\circ} \mathrm{C}\right)\end{array}$} & \multicolumn{3}{c}{ Resistivity of infiltrated and pure RSSC (ohm cm) } \\
\cline { 2 - 5 } & $\mathrm{RSSC}$ & $(+5 \% \mathrm{VC})$ & $\left(+5 \% \mathrm{~B}_{4} \mathrm{C}\right)$ & $\left(+5 \% \mathrm{MoSi}_{2}\right)$ \\
\hline 25 & 0.599 & 0.226 & 0.102 & 0.288 \\
100 & 0.557 & 0.220 & 0.097 & 0.282 \\
150 & 0.535 & 0.216 & 0.090 & 0.268 \\
200 & 0.514 & 0.208 & 0.087 & 0.255 \\
300 & 0.469 & 0.198 & 0.079 & 0.243 \\
400 & 0.462 & 0.173 & 0.052 & 0.223 \\
500 & 0.441 & 0.149 & 0.002 & 0.191 \\
600 & 0.434 & 0.138 & 0.042 & 0.158 \\
700 & 0.429 & 0.126 & 0.096 & 0.135 \\
800 & 0.422 & 0.121 & 0.137 & 0.120 \\
900 & 0.419 & 0.117 & 0.170 & 0.109 \\
1000 & 0.404 & 0.077 & 0.199 & 0.097 \\
\hline
\end{tabular}




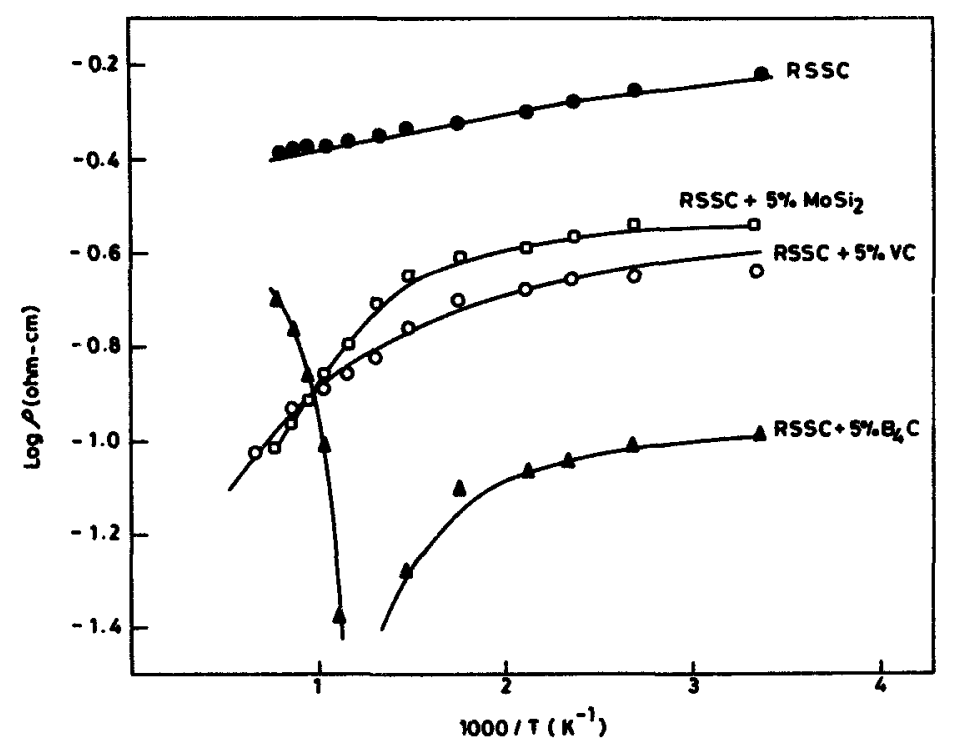

Figure 3. Plot of $\log \rho$ vs $1000 / T$ for doped and undoped reaction-untered silicon: carbide.

nevertheless was always less than that of undoped material. Increase in resistivity with increase in temperature up to $900^{\circ} \mathrm{C}$ followed by reduction is reported (North) and Gilchrist 1981) which is contradictory to our observations. This may be due to the differences in the free silicon content. Our samples contained approximately $8 \%$ free silicon whereas their (North and Gilchrist 1981) samples had 16\% free silicon. Hence the resistivity vs. temperature behaviour is dominated by the silicon phase. Further reduction in the electrical resistivity of infiltrated RSSC is attributed to the presence of highly electrically conducting infiltrants in the silicon phase as seen in the micrograph (figure 2).

\section{References}

Forrest C W, Kennedy P and Shennan J V 1972 in Special ceramics (cd.) P Popper (Br. Coram. Res. Assoc.) vol. 5, p. 99

Kuznetsova V L and Bresker R I 1972 Ogneupory 553

North B and Gilchrist K E 1981 Am. Ceram. Soc. Bull. 60549

Oleinik G S and Shipilova L A 1975 Poroshk. Metall. 933

Pick A N 1979 Trans. J. Br. Ceram. Soc. 7813

Popper P 1960 in Special ceramics (ed.) P Popper (London: Heywood) p. 209 